\title{
A model for cross-institutional collaboration: how the intercollegiate biomathematics alliance is pioneering a new paradigm in response to diminishing resources in academia
}

\author{
Olcay Akman a and Megan Powell ${ }^{b}$ \\ aDepartment of Mathematics, Illinois State University, Normal, IL, USA; bepartment of Mathematics and \\ Computer Science, University of St. Francis, Joliet, IL, USA
}

\begin{abstract}
We present an emerging model of shared academic, intellectual and infrastructure resources that addresses the need for institutions to sustain their educational and scholarship missions under everdeclining funding. The (IBA) was created in 2014 by Illinois State University for this purpose, eventually growing to a state-recognized 'Center for Collaborative Studies' in 2017. As the impact of the IBA continues to expand, it is on its way to become a new education paradigm in response to diminishing resources, and it can serve as a model to foster collaboration for other fields of mathematics.
\end{abstract}

\section{ARTICLE HISTORY}

Received 15 November 2017

Accepted 12 February 2018

\section{KEYWORDS}

Institutional collaboration; intercollegiate biomathematics alliance; community curriculum; shared resources; research workshops; IBA; undergraduate research

\section{Introduction}

For well over a decade, higher education has been suffering financially, socially and politically. Research universities, regional public universities (RPU) and liberal arts colleges are all under similar pressures to accomplish their missions with steadily diminishing resources and in increasingly unsympathetic environments. Neither research nor teaching activities have been spared from the chronic lack of state or federal funding and support. For example, state spending on public colleges and universities remains well below historic levels. Overall state funding for public two- and four-year colleges in the 2016-2017 school year was nearly $\$ 9$ billion below its 2008 level, after adjusting for inflation (see Figure 1). As a result, higher education institutions have had to balance budgets by reducing faculty, limiting course offerings, and in some cases, by closing campuses. Surviving academic units have struggled to maintain academic standards, due to the impact of reduced funding that causes both educational and research activities to suffer.

The field of mathematical biology is not isolated from the pressures of constantly diminishing funding. In fact, the field is even more prone to suffering from the lack of institutional funding due to its collaborative nature and its dependence on a diverse group of disciplines. The increasing popularity of the field has brought the need to develop mathematical biology 


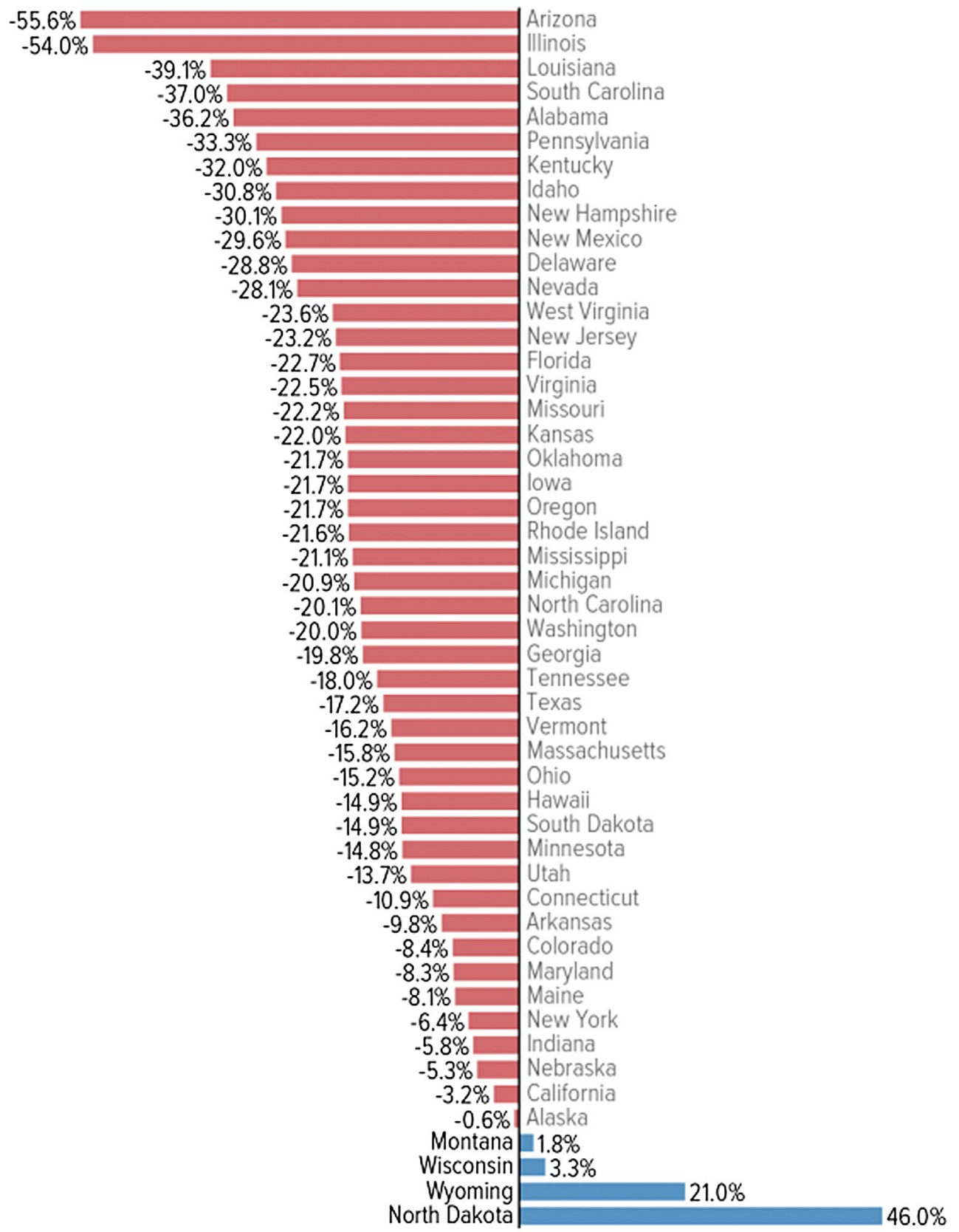

Figure 1. Per cent change in state spending per student, inflation adjusted (2008-2016).

programmes, both as new curriculum additions and research emphases, to the forefront for a wide spectrum of colleges. Coincidentally, under the circumstances caused by decreasing institutional resources, introducing new programmes - either as educational components or new research programmes - have become more challenging, especially due the fact 
that mathematical biology is dependent on more resources than a single department or programme can provide.

\section{Alliance components}

The seeds of a comprehensive academic collaborative entity addressing the discipline-specific needs of mathematical biology programmes were planted in early 2014 at Illinois State University (ISU), with the creation of the Intercollegiate Biomathematics Alliance (IBA). The goal of the IBA was to form a network of dues paying member institutions that served as a nurturing environment for all by pooling their academic, intellectual and infrastructure resources. These resources were then made available to all members in terms of research and curriculum support. As a result, each of the contributing institutions has become a stakeholder in an endeavour where their students and mathematical biology faculty have unprecedented access to a broad spectrum of community-based support, which we shall talk about in detail.

The following highlight the main components of the IBA's mission.

\subsection{Research workshop}

The Cross-institutional Undergraduate Research Experience (CURE) workshop is a unique opportunity for students to experience how conducting research works, experiencing the entire process from its inception to dissemination, including cross-institutional collaboration, scientific writing, presentation and publication steps. The first CURE workshop was held at ISU during the first extended weekend (Thursday-Sunday) of June 2016, where participation was at 20 students, with 10 faculty members giving presentations on possible research projects. The second CURE was attended by 10 students and 6 faculty members in June 2017. In both cases the application process was very rigorous, and the numbers were kept at an optimum amount for productivity. Presentations included a range of mathematics and biology topics, such as basic epidemiological modelling, agent-based modelling, waterborne diseases and neural networks. This workshop's flexible content allows the participants to engage in inclusive and diverse research projects especially designed to accommodate several faculty mentor(s)-student researcher(s) groups. Over half of the IBA CURE workshop student participants have presented at the annual Symposia on Biomathematics and Ecology Education and Research (BEER) on projects started at the workshop. In particular, one participant won the BEER conference first annual Outstanding Undergraduate Research award for his work on modelling devil facial tumour disease in Tasmanian devils after the first CURE workshop. He was invited back the next year, and gained so much insight from participating in biomathematics research that he ended up pursuing an $\mathrm{MD}-\mathrm{PhD}$, instead of continuing with his previously chosen career path, which was to become a physician assistant! Students participating in CURE have gone on to pursue medical school, veterinary school and graduate programmes in biochemistry, mathematics and biology. The workshop experience continues to have a lasting impact on students' academic achievements and goals. The IBA is planning to have institutional members host the CURE workshop in rotation, hence giving host locations a special forum to promote their own programmes. In addition, the IBA publishes a unique biomathematics undergraduate research journal, 
Spora, where students whose paths cross IBA activities (as well as others all over the world) can publish their research.

\subsection{Community curriculum}

The IBA coordinates course offerings by member institutions that can be taken virtually by students at other IBA schools. Courses that have already been offered to member institutions include Data Science, Quantitative Biomathematics, and Probability and Statistics. The IBA also funds the technological means needed to support these cross-institutional curriculum offerings, such as access to online conferencing tools and motion tracking cameras. There will soon be an interactive website that coordinates these efforts.

\subsection{Faculty research support}

The IBA frequently coordinates and funds collaboration retreats for faculty to achieve high professional development goals and conduct quality research. To address the needs of computing-intensive research efforts, the IBA also maintains a high-performance computer at ISU, which is available exclusively to members. As part of its commitment to the dissemination of research and educational advancements in mathematical biology, the IBA additionally supports a wide range of research activities such as sponsoring the Midwest Mathematical Biology Conference and the Symposium on Biomathematics and Ecology Education and Research, and funding article publication charges for its members, including in the IBA-sponsored and peer-reviewed Letters in Biomathematics journal for new research in biomathematics.

\subsection{Community-based graduate curriculum}

In fall 2018, the IBA will launch a graduate certificate programme built on a community curriculum where students will have access to online programmes in mathematical biology. The programme combines the resources of IBA institutions to offer three tracks of study designed with a spectrum of student needs in mind. The cross-institutional structure of the programme allows a wider variety of options than a single school would be able to support. Students are able to choose an online programme designed to prepare them for the workforce, serve as a bridge programme for further graduate study, or increase their competitiveness when applying to medical programmes. This is a unique approach in mathematical biology and has potential to inspire other fields or groups of institutions in delivery of education.

\section{Institutional impact}

The IBA continues to grow since it has joined the ranks of well-known organizations supporting the mathematical biology community, such as the Mathematical Bioscience Institute (MBI) and the National Institute for Mathematical and Biological Synthesis (NIMBioS), with an extended and unique goal to support both research and curriculum development. Colleges and universities with different missions all benefit in different ways from participation in the IBA. 


\subsection{Liberal arts colleges}

Private liberal arts colleges, such as IBA institutional members Marymount University and the University of St. Francis, are often tuition-driven and have limited resources for research. Furthermore, their faculty typically have large teaching loads but little funding for travel for collaboration purposes. Small departments demand diverse faculty backgrounds, giving a low likelihood of finding multiple faculty in a single field. Therefore, the need for networking opportunities for faculty to find productive collaborations is high. The IBA provides a platform for interactions between mathematical biology faculty at different types of institutions. These interactions, in turn, lead to a meaningful understanding of how expertise among faculty can be shared to provide productive research collaborations. The IBA has funding to support faculty publications in open-access journals and provides access to journal collections, which may otherwise prove to be prohibitively expensive. Faculty in departments without graduate programmes are routinely invited to serve as co-advisors or committee members for graduate students of other IBA member schools. These activities allow undergraduate faculty to engage in meaningful research experiences not available at their home institutions.

The opportunities that IBA provides are not limited to faculty engagement but extend to student-oriented activities as well. Undergraduate research experiences are becoming increasingly important for undergraduate students to advance after graduation. Traditionally, research experiences for undergraduates (REU) and other summer research programmes have provided these opportunities, but such programmes are becoming increasingly competitive or otherwise unattainable for students of liberal arts colleges. Thus, the IBA regularly hosts workshops (see CURE above) as well as spontaneous small meetings and brings motivated undergraduate students and faculty together across institutional and discipline boundaries. Through these workshops, students' academic experiences are enriched beyond what their home institution could provide. As a result, some IBA students have been able to significantly expand their career goals. For instance, we have mentioned that a particular student decided to pursue an MD-PhD in infectious diseases after engaging in IBA research activity, as opposed to becoming a Physician's Assistant as previously planned. This example highlights the direct impact the IBA has on students' scientific horizons.

The student-oriented opportunities are not restricted to research. One of the most unique activities of the IBA is the community curriculum, where students may take courses across institutional boundaries. This expands the possibilities for students who do not have access to a wide range of course offerings. In this manner, the IBA allows students to experience opportunities that are available at large institutions while still receiving the personalized attention of a small college environment.

\subsection{Regional public universities}

RPUs such as Illinois State University and the University of Wisconsin-La Crosse often lack the resources of research universities, but commonly have scholarship demands similar to those in such institutions. We note that with growing interest in building graduate programmes, RPUs are becoming more dependent on additional academic resources. Moreover, they are likely to have more diversity in the interests of their graduate students than the expertise of their mathematical biology faculty. To address this imbalance between readily 
available resources and demands on faculty at RPUs, the IBA has adopted a vision of creating high-level research in a collaborative environment: research groups that are productive and accessible to faculty at all stages of their careers.

The community structure of the IBA readily offers an avenue to develop more programmes that are robust by fostering synergistic connections within the IBA network. This includes relationships with schools that have abundant faculty to serve as co-advisors and schools without graduate programmes, where qualified faculty may be looking for opportunities to mentor graduate students. Similarly, faculty at schools with only master's programmes can gain experience working with Ph.D. students from other IBA institutions when they serve on dissertation committees or when they are engaged in student-based research at the doctoral level. On the other hand, as new graduate programmes are established, a strong base of undergraduate students is needed to populate these programmes. The IBA network provides RPUs a recruitment platform to connect with motivated and qualified students. The well-structured interactions among IBA institutional members can and do provide a seamless transition for students into advanced degree programmes. This foundation further helps RPUs to develop new innovative courses that may not be in sufficient demand within a single institution. Through the community curriculum, students at IBA institutions can take courses offered by other IBA schools, such as Introduction to Biomathematics. As a result, students at schools with limited course offerings may be motivated to take new and intriguing classes at RPUs, hence increasing enrolment as well as allowing new courses to get off the ground.

\subsection{Research universities}

Research universities (RUs) such as Arizona State University usually have ample resources for their faculty to pursue their research, but mathematical biology faculty may still be limited in the number of accessible collaborators. The IBA can help connect faculty with interests overlapping mathematical biology with those whose sole interest is mathematical biology for a mutual benefit. Computing needs for RU faculty research can be high, but access to computing facilities may not be available or accessible at their institutions. The IBA offers easy access to strong computing power for high-level computation needs. Additionally, RU faculty have access to a wide network of highly motivated IBA undergraduate and graduate students, and can provide expertise to those students, who will benefit immensely from their mentoring.

\section{Concluding remarks}

The successful introduction and growth of the IBA can serve to inspire other fields to generate similar collaborative programmes to help promote scholarship and education. In just three short years, the IBA has created research opportunities for dozens of students, fostered collaborations between faculty across the country, helped schools in remote areas develop fruitful connections, and formed the first community-based mathematical biology curriculum in the state of Illinois. We should finally mention that the IBA, in turn, came to existence at an institution where a few interested faculty members from the Department of Mathematics and the School of Biological Sciences were committed to creating and growing an inter-disciplinary programme. This started with the creation of a master's programme in 
biomathematics (a Program of Excellence) that was administered jointly by the two entities in 2007 and has continued to flourish since its inception. These devoted faculty members sought to expand beyond graduate education at a single school and their continued efforts have grown the IBA to a network of ten schools in just a few years. This review serves to report on the contribution of the IBA to mathematical biology education in an environment where cross-institutional partnerships are paramount and mindful individuals can make a difference in the higher education landscape.

\section{Acknowledgements}

We would like to thank the reviewer for detailed comments and suggestions for improvement of the manuscript.

\section{Disclosure statement}

No potential conflict of interest was reported by the authors.

\section{Reference}

Percent change in state spending per student, inflation adjusted. (2008-2016). Retrieved February 13, 2018, from https://www.cbpp.org/research/state-budget-and-tax/funding-down-tuition-up 